\title{
LA CULTURA JUVENIL SE HA HECHO SECUNDARIA, PERO AUN ES UNA ALLEGADA...
}

\author{
ASTRID OYARZÚN*
}

\section{INTRODUCCIÓN}

EL TEMA JOVEN Y educación, y cada uno por sí sólo, han adquirido una significativa visibilidad e interés en el debate público y académico en este último año. Por lo menos de lo que yo tengo conocimiento, se han realizado más de 30 iniciativas asociadas a este actor, entre actividades de difusión y diálogo sobre los jóvenes, seminarios sobre los jóvenes, estudios académicos sobre los jóvenes y ejecución de programas y proyectos de distintos ministerios destinados a los jóvenes. Al respecto, me gustaría señalar algunos.

* Hace algunos meses (1999) se realizó en la ciudad de Rosario, Argentina, el seminario «Políticas locales de juventud en las mercociudades».

* El INJUV dispondrá de aquí a finales del 1999 de más de 10 estudios temáticos sobre la realidad juvenil en el ámbito de la educación, mujer joven, trabajo, tiempo libre, sobre la oferta gubernamental dirigida a los jóvenes, etc.

* El mismo INJUV, editará durante el 2000 el Segundo informe 
nacional de juventud, un interesante documento que esperamos dé cuenta del estado de la política social en este ámbito.

* Hace un par de meses la Universidad Cardenal Raúl Silva Henríquez (Ex Universidad Blas Cañas), inauguró su Centro de Estudios en Juventud (CEJU).

* Durante el año 1999 la Universidad de Santiago y el INJUV, se encuentran desarrollando el Primer Diplomado en Juventud en nuestro país.

* Hace algunos días también salieron a la luz pública los resultados de dos estudios de juventud: «Jóvenes del siglo XXI», realizado por la cadena de televisión MTV y otro del Instituto IDEA de la Universidad de Santiago.

* Durante el mes de septiembre del 1999 se realizó el Primer Encuentro Nacional de Oficinas Municipales de Juventud, cuyo objetivo ha sido el de fortalecer la institucionalidad de juventud en el espacio municipal.

* El 18 y 19 de octubre de 1999, se desarrolló un Seminario Internacional sobre Juventud en la Universidad Cardenal Raúl Silva Henríquez.

* En el mes de noviembre se realizó en Santiago, en la sede de la CEPAL, un Encuentro Internacional de Juventud: «Mejores prácticas en proyectos juveniles del cono sur».

* Dos datos más. Durante este año se está desarrollando una nueva faceta del programa de Capacitación Laboral Chile Joven, del Programa Local de Desarrollo Juvenil y el Programa Encuentro Joven. En total y en conjunto estos programas no convocaran a más de 20.000 jóvenes como beneficiarios de la política que deviene del FOSIS.

* El INJUV para el año 1999, tiene un presupuesto aproximado de 1.300 millones de pesos. Cifra similar a lo que se gastó en el Encuentro Continental de Jóvenes y similar a lo que aportó el gobierno en el Jamboree Internacional que se realizó a principios de año.

* Y, hoy nos hemos encontrado en este seminario, que nuevamente se relaciona con los jóvenes y que se ha denominado «Políticas locales de juventud».

Todas estas iniciativas han tenido —a lo menos- un propósito significativo, conocer más a los jóvenes o de los jóvenes. No ha habido una década en la historia de nuestro país, en que los jóvenes hayan sido uno de los objeto de más «interés» de las distintas discipli- 
nas del conocimiento. Ello se explica, por un lado, por lo nuevo del tema, efectivamente, los jóvenes en nuestro país comienzan a tener relevancia social, desde la década de los 70 en adelante. Pero también, porque este tipo de población, durante buena parte de la década de los 80 y toda la década de los 90 se ha caracterizado por hacerle ruido al sistema social, porque no logra ajustarse a los requerimientos que de ella se esperan. Estamos hablando específicamente de la capacidad de los jóvenes de integrarse al sistema social. Volveremos sobre este tema.

Pero además, porque ha sido en esta década, en donde más ha existido la posibilidad de levantar una política social especialmente para este sector, a propósito de la reestructuración de la política misma. Esto, como podremos ver en este seminario, ha tenido ciertamente sus ventajas y desventajas, después de casi diez años de intento.

Estos tres elementos, es decir, lo nuevo de lo joven como tema, la existencia de una - aunque precaria - institucionalidad de juventud y la visibilidad de los jóvenes mismos como actores en tensión con el sistema social, sin duda han generado a lo menos algunas preocupaciones y, eso es otro dato a tener en cuenta.

Luego, cuando uno se enfrenta al binomio joven y educación - quiero decir como proceso de reflexión con otros- tiene diversas posibilidades para abordarlo.

Lo primero entonces, es que no vamos a hablar de otra cosa sino que de la educación de los jóvenes. O dicho más claramente, nos ubicaremos en el contexto de que la educación media es la educación de los jóvenes. En nuestro país existen en estos momentos más de 700 mil hombres y mujeres estudiando, conviviendo y compartiendo unos modos de ser joven y de ser estudiante en los más de mil liceos y colegios del país. Esa pareciera ser el segundo dato interesante, aunque no siempre es tan obvio, ni tan reflexionado, ni tan compartido.

Lo segundo, es que no vamos a hablar de cualquier joven y estudiante. Me procuparé mucho más de aquellos jóvenes que ven más amenazada su educación, su calidad de educación y con ello su calidad de integración al sistema social vía la educación. Básicamente me estaré refiriendo a la educación subvencionada, particular o municipalizada y, en especial a esta última.

Lo tercero, es que se hace necesario, por lo menos en el contexto planteado, intentar abrir dos caminos de reflexión. Por un lado, una perspectiva más global que está asociada a los sentidos de la educación y a los efectos que tiene la escolarización en este segmento 
juvenil. Y en segundo lugar, una perspectiva más interna del sistema escolar, más asociado a lo que ocurre hoy con el tema cultura juvenil y cultura escolar.

\section{RESPECTO DE LOS SENTIDOS DE LA EDUCACIÓN}

La demanda de las personas y de los grupos sociales respecto de la educación, sea cual fuese su origen y características, se expresa a través de dos tipos de orientaciones centrales.

a) Primera orientación. La constitución del grupo y su funcionamiento interno

Todo grupo de personas ubicadas en una estructura social grupal, buscan y desean saber quiénes son, y cómo mejorar su funcionamiento como colectivo. A lo primero se le ha llamado principio de identidad de los grupos; a lo segundo principio de participación.

Identidad: dice relación con los procesos de autoconciencia, los discursos culturales, los procesos de formación. La gente busca una afirmación colectiva en algún tipo de identificación y, a ella se refiere buena parte de la demanda educacional en períodos de autoritarismo y de homogeneización social impositiva.

Participación: se refiere al conjunto de valores horizontales o dialógicos. Es la posibilidad de los grupos de hacer vida propia, de tener instancias de toma de decisiones propias. En este sentido, la educación juega un papel sustantivo no sólo en la enseñanza de la participación y la democracia, sino principalmente en su ejercicio.

b) Segunda orientación. Todo grupo también busca algún tipo de transformación, ya sea individual o colectiva

Ello ocurre vía la movilidad social o a través del simple ascenso social. Principio de modernización. La segunda vía de transformación que puede implicar un cambio de posición del grupo con respecto a otros, su transformación como colectivo, es el principio de cambio social (Bengoa, 1987:28).

La modernización: se refiere a la adquisición de nuevos conocimientos que permitan la transformación, la movilidad ocupacional de las personas, la movilidad social de un grupo, ya sea directamente o por la vía del cambio generacional (educación para los hijos). No cabe 
duda, de que éste es el aspecto más evidente de la demanda educativa. Las personas que no saben de educación creen y reducen a este eje toda la empresa educacional.

El cambio social: se refiere a la transformación global de la sociedad. Sea cual fuese la sociedad de la que hablamos y su período histórico, los grupos y las personas demandarán y requerirán espacios de discusión, aprendizaje y confrontación de los caminos para el cambio de las sociedades.

Tomando en consideración estos cuatro principios identidad, participación, modernización y cambio social—, nuestra perspectiva, será atribuirle a la educación, un papel de formación social y por agregación, un papel instrumental asociada a la adquisición de competencias y habilidades que permita una adecuada inserción social de los jóvenes en la sociedad.

A lo largo de la historia, el contenido de la educación ha sido siempre, al mismo tiempo, moral y práctico. Reviste en parte la forma de valores y mandamientos, en parte es el cultivo de capacidades, conocimientos y habilidades (MINEDUC, 1994a). Sin embargo, más allá de todos los enfoques y necesidades sociales, en educación, lo fundamental es que prevalezca que el centro del accionar educativo es el sujeto de la acción educativa, en este caso, jóvenes. Por ello, una de las preguntas centrales de hoy en día, dice relación con aproximarse a determinar hasta dónde el sistema educacional ha podido responder a los requerimientos que socialmente se le hacen respecto del mundo juvenil, teniendo en cuenta los principios anteriormente enunciados.

\section{UNA PERSPECTIVA MÁS GLOBAL}

Entonces, en este contexto, necesario es introducir algunos antecedentes, esta vez más referido al binomio joven y educación y más referido a este eje de transformación y, en concreto al principio de modernización.

* Primer antecedente. En la educación media chilena existen alrededor de 753.250 jóvenes, es decir, un $21.0 \%$ de la juventud chilena está en el sistema educacional.

* El 51.0\% de la matrícula de enseñanza media está en los liceos de dependencia municipal y sólo un $10 \%$ en liceos particulares pagados (MINEDUC, 1999:86).

* La cobertura de la educación media es en promedio (1996), 
de un 85.0\%; sin embargo, la cobertura de educación para el primer quintil de ingreso alcanza a un $76.3 \%$ y para el quinto quintil un $97.2 \%$. Es decir, poco más de veinte puntos de diferencia entre los quintiles extremos (MINEDUC, 1999:88).

* La cobertura promedio en las zonas urbanas es de un 89.0\%, en cambio, en las zonas rurales es de un 68.5\% (MINEDUC, 1999:88). Nuevamente una significativa diferencia.

* En Chile, 9 de cada 10 estudiantes reciben financiamiento del Estado para cursar su educación media. El monto de la subvención promedio mensual que el Estado paga por estudiante asciende a la suma de \$19.791 (MINEDUC, 1999:87).

* El 55.3\% de los estudiantes que egresan de la enseñanza media repite al menos un curso. Esta situación en la educación municipalizada sube a un 63.5\% (MINEDUC, 1999:89).

* Los jóvenes se demoran en egresar de la enseñanza media un promedio de 5.2 años. Los jóvenes de la educación municipal lo hacen en 5.7 años. Y, la misma situación en un colegio particular pagado llega a 4.3 años (MINEDUC, 1999:89).

* Los jóvenes hombres que abandonan sus estudios lo hacen principalmente porque decidió trabajar (29.7\%) o por problemas económicos (27.9\%) (MINEDUC, 1999:90).

* Las mujeres jóvenes que abandonan el sistema escolar lo hacen por problemas económicos (18.0\%), porque se embarazó (16.3\%) o porque se casó (13.0\%) (MINEDUC, 1999:90).

* Según los jóvenes estudiantes, la situación más conflictiva que vive en su liceo está asociada a problemas en la disciplina (31.4\%) (MINEDUC, 1999:91).

* Por último, un dato sobre el componente joven del Programa MECE-MEDIA. La encuesta MECE-MEDIA de 1997 del Ministerio de Educación, indicó que 162 mil 279 jóvenes participaron en las Actividades Curriculares de Libre Elección (ACLE). Con un promedio de participación de 158 jóvenes por liceo. El 36.9\% de estos talleres se realizó en el ámbito del deporte (MINEDUC, 1999:98).

Desde el año 1990, especialmente desde 1995 en adelante, ha habido un claro acuerdo en el diagnóstico sobre el sistema educacional y los efectos de él en los jóvenes. Cuál es: que la enseñanza media además de presentar problemas de inequidad, ineficiencia y falta de calidad, padece una crisis de orientación y de relación con su medio externo. Es decir, existe una fuerte tensión entre el sistema de educa- 
ción media de los jóvenes y el sistema de educación superior; entre el sistema de educación media y el sistema productivo y el mercado de trabajo; entre el sistema de educación y el sistema de la información y el conocimiento.

Luego, la pregunta que aparece siempre relevante en esta perspectiva más global, está relacionada con el destino de los egresados del sistema educacional y sobre todo con el destino de aquellos que no lograron mantenerse en el sistema. Como es sabido, la variable que más discrimina en los procesos de inclusión/exclusión de los jóvenes al sistema social, es justamente la variable educación. Hoy en día el sistema educacional no tiene problemas de cobertura en el ámbito de la educación, sino que más bien problemas de acceso y desigualdad de oportunidades en los resultados.

Un joven que pertenece al primer quintil de ingreso (el más pobre) presenta una escolaridad promedio de 8.9 años de permanencia en el sistema educacional, en comparación al quinto quintil de ingreso (el más rico), que permanece 13.3 años en promedio en el sistema educacional (MIDEPLAN, 1997).

La diferencia entre un tipo de joven y otro es bastante significativa, sólo viéndolo desde un punto de vista más cuantitativo, sin entrar es sus aspectos más cualitativos para percibir las calidades de educación que están recibiendo uno y otro sector. Este antecedente da más claridad para confirmar que el problema no es de cobertura, sino que se relaciona con el tipo de proceso que se genera en el sistema educacional y sus esferas relacionadas, para favorecer un mejor proceso de integración de los jóvenes pobres del país. Más aún, los niños y jóvenes populares, no tienen la dificultad de ingresar al sistema escolar, su dificultad radica más bien en mantenerse en él, en no desertar del sistema educacional y, lo segundo, es que efectivamente ese proceso de educación que están recibiendo le permita mejores condiciones de integración al sistema social, especialmente al mundo del trabajo.

Allí podría plantearse la discusión/tensión sobre las lógicas que debieran imperar de parte de la institucionalidad y sus políticas públicas, tanto en su discurso como en su práctica. Tensión que se ubica exactamente en la relación: igualdad de oportunidades en el acceso, o igualdad de oportunidades en los resultados. Es decir, todos los niños y jóvenes tienen libre acceso a la educación; o todos los niños y jóvenes tienen la misma posibilidad de culminar su enseñanza, sin importar la condición económica de ellos. 
Pero se han hecho esquivas ciertas precisiones terminológicas y prácticas de cómo enfrentar estas situaciones de desventaja social. Por ejemplo, a tiempos actuales el lema que se reza está centrado en indicar que la forma privilegiada de asegurar la equidad es a través de la igualdad de oportunidades.

Si vinculamos la dimensión educacional con las posibilidades de obtención de empleo y calidad de salario de éste, hay una estrecha relación, donde la premisa tiende a confirmarse -en términos generales- pues, a mayor educación, mayor posibilidad de obtener un empleo y un empleo de mejor remuneración.

Esta situación, puede verse claramente en la curva de años de escolaridad por nivel de ingreso, con mayor notariedad a partir de los 12 y 14 años de escolaridad o más, en donde el ingreso comienza a subir notoriamente.

Entonces, junto a la educación —y en la mayoría de los casos, dependiendo de ella-, el mundo del trabajo representa otra de las dimensiones fundamentales en que se expresa la exclusión social de los jóvenes populares. Cuando hablamos de educación, de calidad y equidad de educación, estamos hablando de que buena parte de los jóvenes que no logren mantenerse en el sistema educacional, tendrán el destino que hemos presentado. Y esto debe ser una preocupación de las actuales políticas públicas.

El diagnóstico que se ha hecho de la educación chilena a propósito de la Reforma Educativa, que ya comenzó a aplicarse en los primeros años medios, está centrado en superar algunos de los aspectos indicados. Y ella es la llamada a corregir estas situaciones de vida que hemos expresado en cifras, pero que representa concretamente a jóvenes que perdieron la oportunidad. Que quedan excluido del sistema social y que pasan a engrosar la fila de los pobres. Creo que ése es el sentido principal de esta reflexión más global cuando estamos uniendo este binomio de educación/joven popular.

Este principio modernizador y que es el más evidente del sistema educacional, no necesariamente alcanza a cubrirse en el caso de los jóvenes más pobres y sus efectos son significativos si no se logra revertir la distancia entre un joven que tienen desventajas sociales y un joven que no las tiene. Pues los pobres no sólo no tendrán acceso a la educación, a la salud, a la vivienda, a una buena alimentación, a un buen trabajo, la mayoría de las veces tampoco participarán de los procesos de toma de decisiones en sus espacios locales; tendrán dificultades para expresar sus intereses, problemas para ser oídos o escucha- 
dos, tendrán poca fuerza para negociar y reivindicar sus derechos. Ser pobres no sólo tiene que ver con los accesos materiales y calidad de ellos, involucra también su posición en la sociedad, su cultura, sus opciones políticas, su vida cotidiana.

Pero aún cuando sabemos todo esto y más acerca de la pobreza, lo que pareciera ocurrir es que cada vez cuesta más definir por dónde puede ir la política social juvenil para estrechar las distancias entre quienes no son un pobre de finales de siglo y quienes sí lo son. Hoy más que nunca, la educación puede y debe, como responsabilidad social, hacerse cargo de los efectos que produce en sus educando una mala calidad de educación, con todo lo que ello implica.

\section{UNA PERSPECTIVA MÁS INTERNA: ENTRE LA CULTURA JUVENIL Y LA CULTURA ESCOLAR}

Más cercana a lo que está sucediendo con los jóvenes en su relación con el sistema escolar. Más cercana al principio de identidad y de participación que aparecen como las demandas menos evidentes de los sujetos, pero las más trascendentales para la vida social.

En la perspectiva del Programa MECE-MEDIA y de la actual Reforma Educativa, existe un dato interesante que me parece necesario recoger, cual es la demanda que se está realizando hacia los establecimientos educacionales para que integren la cultura juvenil a la cultura escolar. Este intento se ha realizado fundamentalmente a través del Componente Jóvenes del Programa MECE-MEDIA y en específico a través de las Actividades Curriculares de Libre Elección más conocidas como las ACLES. Dos datos interesantes en la actual política de educación. Primero, se instala la idea de lo joven — como tema - en el sistema educacional y segundo, existe un componente para ellos. Potente señal ante una cultura escolar que habla más bien de estudiantes y no de jóvenes. Potente señal respecto a la inclusión - aunque simbólica todavía - de los jóvenes más cercana a la vida del liceo.

¿Qué es lo que hace que en la década de los noventa se plantee la necesidad de integrar la cultura juvenil a la escolar? ¿Qué significados tiene para el sistema escolar y para los propios sujetos que esta integración se produzca? ¿Para qué sirve? ¿Quiénes hacen esta demanda? Son preguntas que surgen cuando uno escucha en las voces de (algunos) profesores y más de la política de educación, de lo importante que es que se realicen esfuerzos en esa dirección. 
Frente a esto la respuesta primera de uno sería, obvio, necesario es porque es en el nivel de enseñanza media donde se encuentran la gran mayoría de los jóvenes del país. Y es la educación media el nivel del sistema escolar que atiende a estos sujetos cuando están en la fase más característica, conflictiva y vulnerable del período juvenil (Weinstein, 1994:263).

Lo segundo que uno diría, es que sí, hasta ahora, la cultura juvenil nunca ha estado presente en el sistema escolar, se ha obviado, no ha existido, o no se ha considerado para realizar los procesos de enseñanza-formación de los alumnos. Tal cual se expresa hoy en día, podríamos decir que los educadores han trabajado, por decirlo de alguna manera, con un tipo de sujeto dividido o, de otra manera, han trabajado con la mitad de un sujeto. ¿Cuál es esa mitad?

Entendiendo que las imágenes son simbólicas, se ha trabajado más bien con la perspectiva de que los alumnos y jóvenes son objetos de enseñanza y, en esta lógica están llamados a consumir instrucción, en donde lo válido es lo que se les enseña y lo que logran aprender de las materias asignadas. Este tipo de relación, generada al interior del sistema escolar, que es unidireccional, no ha requerido - hasta ahora- conocer nada de sus consumidores de instrucción ni aprender nada de ellos.

Esta es una de las paradojas con las cuales se ha enfrentado la década de los noventa y es la que ha creado un sinnúmero de tensiones contenidas en los propios establecimientos educacionales o contenidas en las propias experiencias de los jóvenes educandos. Y es justamente esta suerte de tensión y la emergencia de situaciones conflictivas al interior de los establecimientos educacionales, lo que ha hecho que en el debate público aparezca como demanda el construir puentes hacia la integración de la cultura escolar y la cultura juvenil.

Pero lo tercero que uno podría decir, es que esta orientación/demanda, está directamente relacionada con una pregunta más profunda: ¿cuál es la concepción y finalidad que se le quiere asignar a la educación en la sociedad chilena de hoy? Y en concreto, preguntarse por cuál es el tipo de joven que esperamos egrese del sistema educacional.

Haciendo una comparación con la Reforma Educacional de inicio del siglo, la educación estuvo fuertemente exigida por los cambios que se requería que operaran en la sociedad, y se ve a la educación como una herramienta y medio para alcanzar esos cambios, de exigencia de justicia social. De diferente modo, la educación actual 
está demandada por la necesidad de un modelo social, que ve en ella un medio para avanzar y alcanzar sus objetivos de modernización.

También es diferente lo que se persigue como producto en el joven alumno. En la primeras décadas de este siglo se buscaba un joven que colaborara y contribuyera al cambio social, por ende se ponía más atención en las potencialidades de los jóvenes. En cambio, hoy se busca un joven que pueda integrarse de manera eficiente al modelo y no pueda ser obstáculo para el desarrollo, lo que repercute en un discurso que pone más atención en las anormalidades que pueda presentar el joven para corregirlas y no en sus potencialidades.

Si uno observa los diferentes estudios, el discurso de la opinión pública y la cotidianeidad misma de los establecimientos educacionales, se aprecia que efectivamente el discurso público e institucional pone más atención en las anormalidades que en las potencialidades de los jóvenes y no sólo el discurso, sino que también sus prácticas educativas están en función de ello. Como ejemplo, sólo consideremos la cantidad de proyectos, campañas, charlas, diálogos que se han hecho en torno al consumo de drogas en los liceos. Sin embargo, está claro a través de distintos estudios que el consumo de drogas en los estudiantes es bastante poco significativo y no constituye uno de los problemas más importantes de los estudiantes. Lo mismo ocurre con otro tipo de conductas sociales consideradas disfuncionales, que han plagado la cultura escolar de una lógica preventiva, asociada al daño social y más concretamente al riesgo social.

Teniendo en cuenta que efectivamente existe riesgo social en mucho de los jóvenes, teniendo en cuenta que es necesaria la promoción de este tipo de iniciativas, lo cierto es que la balanza se ha inclinado perversamente hacia una concepción generalizada de joven con daño social, impidiendo ver las potencialidades que trae su cultura juvenil. Es este tipo de concepción la que se ha instalado en la cultura escolar y la que desnaturaliza - a mi entender- una mejor comprensión acerca de lo que se está entendiendo por integración de la cultura juvenil a la escolar. Aquí hay un elemento que merece una profunda reflexión. Revisemos el itinerario que se siguió.

El Programa MECE-MEDIA señala la existencia de un desconocimiento generalizado de la cultura juvenil y la falta de una clara voluntad de incorporarla en el sistema educacional. La cultura escolar vigente - dice - tiende a considerar escasamente que los alumnos del nivel secundario constituyen un grupo etáreo singular, con sus códigos culturales y desafíos psicosociales específicos. 
Luego, exige de las unidades educativas la actualización de sus propuestas de contenido adecuando el curriculum a las realidades y especificidades de los estudiantes.

Amplía el horizonte del quehacer educacional al definir la cultura escolar como el ámbito idóneo, para la corrección de las conductas transgresoras (drogadicción, alcoholismo, delincuencia) que complejizan la estabilidad social del país.

Asume la implementación de la Jornada Escolar Completa Diurna, como ámbito de optimización del tiempo libre de los jóvenes y con ello, como mecanismo preventivo de eventuales desviaciones conductuales en un medio social que se asume como hostil.

Y realiza un examen crítico acerca del comportamiento juvenil popular en la enseñanza media, el que se puede sintetizar de la siguiente forma (MINEDUC, 1994b).

\section{a) Mal uso del tiempo libre (fuera del liceo)}

El mal uso del tiempo libre fuera del liceo es considerado como un grave problema social, ya que se asocia no sólo con el ocio y la vagancia, sino que también con la conducta tipificada del joven como riesgo social:

- Desarrollo de acciones rutinarias, pasivas y poco creadoras durante su tiempo libre.

- Agrupamiento espontáneo en calles, formando los tipificados «grupos de esquina».

- $\quad$ Altos índices de exposición a la TV.

- $\quad$ Escasa o nula participación en organizaciones y grupos, o bien, de desarrollo sistemático de deportes.

- $\quad$ Aumento de riesgos psicosociales asociados a las drogas, el alcohol y la violencia sin buscar el desarrollo personal. Búsqueda «transgresora» de salir de la monotonía, aburrimiento y falta de actividades.

b) Mal uso del tiempo libre (dentro del liceo)

El mal uso del tiempo libre dentro del liceo se asocia a una insuficiencia cuantitativa y cualitativa de actividades extraescolares:

- Impera una visión de que las actividades extraescolares son secundarias y marginales. 
- La participación de los estudiantes en las actividades que existen es minoritaria.

- $\quad$ Escasa incorporación de los intereses y gustos de los adolescentes y jóvenes.

- De lo anterior resulta una falta de identificación o sentido de pertenencia con el liceo, lo que promueve una desvinculación y desmotivación con la comunidad escolar general.

c) Mal uso de la información entre el liceo y la realidad exterior

El mal uso de la información se asocia a un enclaustramiento del establecimiento y un aislamiento generalizado de los estudiantes con la realidad del mundo externo:

- Poca fluidez en la relación con diversos actores y sectores externos al sistema escolar.

- Escasez de vínculos con congéneres de otros establecimientos, padres y apoderados.

- $\quad$ Marginación de las problemáticas sociales.

- Creación de falsas expectativas, ya que predomina una orientación mayoritaria hacia la universidad, con una consecuente desvalorización de alternativas de trabajo existentes.

Entonces, el potencial de riesgo social, la pérdida de identidad con el establecimiento y la creación de falsas expectativas en relación al futuro, constituyen todos ellos elementos derivados de las problemáticas juveniles. Consecuentemente con los objetivos propuestos por el Programa, se sugieren algunas orientaciones para la acción (MINEDUC, 1994b:59-60):

- Ampliación del espacio-tiempo para el desarrollo juvenil dentro del establecimiento secundario.

- Renovación de la educación extraescolar, reforzando su impacto en la educación y formación de los jóvenes.

- Maximización del uso de recursos e infraestructura disponible en función del desarrollo de los jóvenes.

- Potenciación de los recursos educativos del establecimiento. 
- Intercambio entre unidades educativas, así como de las unidades educativas con otras instituciones noescolares, en la perspectiva de formación de un sistema abierto e intercomunicado para desarrollar el quehacer educativo extraescolar con jóvenes.

A nuestro juicio, el tema de integración de la cultura juvenil a la cultura escolar tiene que ver con volver a poner en el aula el desafío de hacernos copartícipe de la construcción de identidad y no fuera de él, como aparece en la propuesta expresada. Esto es casi una exigencia y una necesidad por parte de los jóvenes.

Un enfoque de educación que no comprenda y no involucre una perspectiva integral del sujeto juvenil, su entorno y sus claves culturales, no tendrá más efecto que el aportar a un buen nivel de instrucción. Pero si se incorpora la capacidad del sujeto juvenil y con ello sus claves identitarias, será posible tener mayor certeza acerca de las tareas, metas y desafíos significantes para cada individuo, para los grupos de jóvenes.

De lo que se trata es intentar salir de un campo de contradicciones que aún se encuentra en proceso de salvar el itinerario de homogeneización, de la estandarización de patrones, de la despersonalización de las formas de comunicación, de regímenes de educación que valoran el orden y la disciplina por sobre el ser y el saber, de la cultura de la domesticación, de la uniformización de los individuos. Es el intento por evitar negar al sujeto juvenil al interior del sistema escolar.

El liceo es el espacio, que a nuestro juicio, justamente por tener la notable ventaja de recibir en sus aula a la gran parte de los jóvenes, puede colaborar más claramente en el proceso identitario de los jóvenes, puede establecer relaciones que colaboren a su desarrollo de sujeto juvenil y por ende a una transformación crecedora entre él y su medio, entre él y sus pares, entre él y su generación, entre él y su comunidad.

Pero esta integración de culturas tiene que recrear los sentidos de la misma y poner sus acentos en el aula y no fuera de él, en las potencialidades de los jóvenes y no en sus incapacidades. Desde nuestra perspectiva, estos acentos estaría relacionados con cuatro elementos.

- La ciudadanía. La mayoría de edad se ha establecido en 
los 18 años y su objetivo ha sido el de dotar a los jóvenes de la facultad de ejercer los derechos civiles, políticos, laborales y comerciales que la ley confiere al otorgar la ciudadanía. Preparar en el aula el ejercicio de la ciudadanía es parte también del encuentro entre estas culturas, hasta ahora disociadas. En tal sentido, se deben reconocer y tomar en cuenta no sólo los deberes de los jóvenes, sino que también sus derechos. Esto es una exigencia a propósito de que no sólo egresan del sistema educacional con un diploma de cuarto año medio, sino que también con un diploma de ciudadano. En este sentido, creemos que el liceo puede y debe dialogar en torno a los derechos culturales de los jóvenes, en torno a la igualdad en el ejercicio de sus derechos civiles y políticos y debe reconocer la especificidad juvenil al interior de los derechos humanos genéricos.

Esto obliga a los adultos a abrirse a la posibilidad de establecer un nuevo tipo de relacionamiento con los jóvenes, en donde, nuevamente, el liceo como institución formadora tiene la ventaja de hacer práctica estas facultades, precisamente por su rol formador.

- La participación. Pero además, el encuentro de estas dos culturas debe poner el acento en generar los espacios necesarios de participación que permitan derribar el muro divisorio entre la cotidianeidad de la escuela y la cotidianeidad extramuros.

La participación no sólo logra su sentido cuando los jóvenes participan en la elección de su centro de alumnos o su directiva de curso, sino que también logra su sentido cuando se reconoce explícitamente la posibilidad de disfrutar de las garantías de estar en igualdad de participación en los deberes y derechos que el liceo propone. Es esta una manera de aportar en la recreación de una cultura integradora y un esfuerzo que tiene un sentido cultural, dado que no sólo se busca aumentar el conocimiento y el aprendizaje en los jóvenes, sino que además, una internalización y una propuesta de cambio, siempre en la búsqueda de un mejor vivir en todos los sentido que recorre la experiencia de ser jóvenes y ser estudiantes.

La participación en aula debe asumir una actitud y comportamiento de libre expresión que recoja los diferentes estados de ánimos que viven los estudiantes; es decir: de logro, de crítica, de disgusto, de satisfacción con lo que les ocurre en la vida del liceo. Porque la participación se valida en la medida en que la tolerancia, la diversidad de opiniones y la autenticidad tienen lugar en ella (Irrazabal et al., 1998:15). 
Por lo tanto, la vemos en su dimensión más integral, no únicamente desde el punto de vista de la socialización y de un mejor uso del tiempo libre. Sí desde un punto de vista integrativo, no desde un punto de vista de asimilar normas que impone el liceo, sino también de proponer, crear y ser respetado en sus proposiciones. Creemos que la participación se debe abrir a los proyectos educativos, reglamentos disciplinarios, calendarios de pruebas, evaluación de profesores, otros. Ello está en el espíritu de la nueva Reforma Educativa también al proponer: «Un sistema adecuado de disciplina en el liceo que promueva el ejercicio de la libertad responsable y la capacidad de autogobierno, con plena participación de las alumnas y alumnos en la definición de normas de convivencia, y de su protagonismo en la vida liceana, constituye una dimensión crucial de la formación ética y el desarrollo personal definidos en los objetivos fundamentales transversales» (MINEDUC, 1998a:25). Desde esta perspectiva nos parece interesante poder distinguir entre una participación más instrumental, entre una participación más institucional y entre una participación más gremial.

- La expresión. La necesidad, el derecho y la capacidad de decir y hacer, es pieza clave en la construcción de nuestra personalidad e identidad. La escuela es restrictiva de esta capacidad. Limita la expresión a aquellos asuntos puramente funcionales a la escolarización; y desde el punto de vista de las formas, lo hace en una relación dominada por el verticalismo y el autoritarismo. En este caso una función formativa clave es proveer los aprendizajes favorecedores de la capacidad de expresar (decir y hacer), más específicamente que los y las jóvenes estudiantes puedan llegar a tener un propio discurso sobre todos aquellos aspectos que les concierne y puedan por esa vía afirmar y construir su propia identidad y cultura juvenil. Ellos son objetivos verdaderamente trascendentes y estratégicos de la educación.

- El género. Se trata de potenciar la identidad de hombre y mujer. El liceo es un fuerte reproductor de cultura y puede ser un gran espacio para una formación que se basa en el respeto a la dignidad e identidad de las personas.

En este sentido, el sistema educacional se ha caracterizado por creer que imparte una educación asexuada, provocando una cierta tranquilidad en los actores responsables del proceso educativo, pues se tiende a percibir la presencia e interacción de los géneros y la sexualidad como conflictiva y alteradora. Pero en la práctica, nuestra educa- 
ción es claramente sexuada.

La perspectiva de la educación ha sido la de enfatizar la preeminencia de un sexo sobre el otro y ella distorsiona los sentidos que tiene la construcción de la identidad y de los roles sexuales en hombres y mujeres. Esta orientación - se cree- que sólo perjudica al sexo femenino, pero también influye negativamente en la identidad masculina al no colaborar en la comprensión del ser hombre y ser mujer. En el aula se tiende a omitir el sujeto femenino en el lenguaje, el número de interacciones de los docentes con los estudiantes del sexo masculino son mayores, es frecuente la atribución de más responsabilidades a los hombres que a las mujeres y los profesores interactúan menos frecuentemente con las mujeres que con los hombres en áreas del conocimiento consideradas poco femeninas.

Este tipo de vivencia presenta una doble dificultad, por un lado, expresan las propias percepciones, valoraciones y definiciones que sobre el género tienen internalizado los profesores; y por otro, es que la socialización a los alumnos y alumnas acerca de los roles se hace a partir del imaginario que cada uno de ellos tiene o se ha construido. Es por ello que para construir una práctica educativa que valore el género, se requiere, fuera de ser explícitos en que los contenidos de género estén presentes a través del proceso formativo, que el sistema y los agentes educativos cuestionen y problematicen sus propias representaciones del ser hombre y ser mujer.

Creemos que efectivamente el principio de identidad y de participación podrían estar relacionados con lo que hoy se está llamando incorporación de la cultura juvenil a la cultura escolar. Sin embargo, retomando las señales que se han entregado a través del Programa MECE-MEDIA y de la Reforma Educativa, todo lo que tiene que ver con estos principios han quedado fuera del currículum escolar y fuera del espacio institucional, fuera del liceo. La cultura juvenil, tal cual se nos presenta ha estado reducida a lo que tradicionalmente hemos entendido como actividades extraprogramáticas y no a los procesos formativos intra-aula, ello a pesar de la propuesta de los objetivos transversales, que por su transversalidad podría estar y no estar en los procesos educativos de los jóvenes.

De este modo en la cotidianeidad de la reflexión docente, la cultura juvenil ha quedado más asociada a manifestaciones coyunturales o situacionales del quehacer y acontecer juvenil que se presentan más bien dispersos, no conformando una integralidad única que en su interior, pueden y deben tener diversidad. En esta mirada se pierde o 
invisibiliza la noción del sujeto, perdiendo dimensiones importantes del tradicional concepto de identidad juvenil que da cuenta de las potencias y las carencias, pero también de las tareas de desarrollo que supone cada joven - hombre o mujer - en particular.

Lo observable es que se ha producido un quiebre o desorientación en el quehacer de la escuela respecto de los jóvenes. En la tradición escolar, la construcción de identidad — con sus limitacionesera una tarea formativa del área específica de orientación, que hoy se tiende a desplazar a la tarea de integración de la cultura juvenil sin vincular la dinámica de ambos procesos.

Por su parte, este nuevo concepto de cultura juvenil, que aparece como una posibilidad de ampliar el de identidad, dotándolo de dinamicidad y de diversidad que tiene la cultura juvenil en cada tiempo, sólo logra instalarse fuera del currículum educacional, desplazando la tarea de formación del ser joven sólo hacia actividades de socialización e interacción entre pares, asociadas fundamentalmente a la variable tiempo libre.

Finalmente, a modo de conclusión, diría cinco cosas para cerrar esta reflexión.

i) Efectivamente, hoy día podríamos decir que conocemos más de los jóvenes, pero no podríamos decir que se hace más por los jóvenes. La política social juvenil aún no logra construirse como tal y, una perspectiva más centrada en el riesgo social no visibiliza las capacidades del sujeto juvenil y no responde a los requerimientos que los jóvenes están realizando respecto de su integración en la vida social.

ii) Los esfuerzos de la política educacional están más centrado en una educación más cercana a la demanda de modernización que exige el actual modelo, que a la demanda de participación e identidad que exigen los propios sujetos juveniles, necesarios también para integrarse al sistema social como ciudadano.

iii) Efectivamente, la diada joven/estudiante, se ha instalado en la política educacional chilena y en la cotidianeidad del aula. Eso ha sido una interesante señal, pero no ha habido espacio en el aula para discutir y reflexionar el sentido más profundo que hay detrás de este tipo de orientación/demanda.

iv) El concepto de cultura juvenil no aclara necesariamente el tipo de joven que se quiere formar para la vida social ni aclara los nuevos roles que se espera cumplan los jóvenes en la cotidianeidad de la vida del liceo. Más bien entra a dejarlos fuera de él, reduciendo su protagonismo a una participación meramente instrumental y funcional 
a la interacción y socialización entre pares, pero no con el resto de los actores del sistema escolar. Se hace necesario recrear el rol que los alumnos tendrán en la nueva educación, no sólo en el sentido de lo que aprenden y cómo van a aprender, sino también como productor y decididor en su aula y en la escuela. El aprendizaje, sobre todo de roles sociales, se aprenden haciéndolos y ejerciéndolos.

v) El liceo se mueve en medio de diversas contradicciones entre la cultura escolar, fuerte, portentosa, llena de miedos y medios, antigua y disciplinadora; y la cultura juvenil, vigorosa y ambigüa, viva, impertinente, que se realiza en los márgenes de la escolaridad, también con miedos, pero con menos medios. La cultura juvenil, se ha hecho secundaria, sabe que el liceo puede ser su casa, pero aún es una allegada.

VIÑA DEL MAR, ENERO DEL 2000

\section{REFERENCIAS BIBLIOGRÁFICAS}

BENGOA, José (1987): La educación para los movimientos sociales. Proposiciones $\mathrm{N}^{\circ} 15$. Santiago: Ediciones SUR.

COHEN, ERNESTO (editor) (1998): Educación, eficiencia y equidad. Santiago: CEPAL/OEA/SUR.

COMITÉ TÉCNICO ASESOR DEL DIÁLOGO NACIONAL SOBRE LA MODERNIZACIÓN DE LA EDUCACIÓN CHILENA (1995): Los desafíos de la educación chilena frente al siglo XXI. Santiago: Editorial Universitaria.

IRRAZABAL, RAÚL et al. (1998): «Un nuevo espacio, nuevas imágenes juveniles. Los consejos de curso: percepciones, valoraciones y expectativas». Documento de Trabajo Nº4. Viña del Mar: Ediciones CIDPA.

MIDEPLAN (1997): «Encuesta de caracterización socioeconómica, CASEN 1996». Santiago: MIDEPLAN.

MINISTERIO DE EDUCACIÓN (1994a): «Informe del comité técnico asesor del diálogo nacional sobre la modernización de la educación chilena». Santiago: MINEDUC.

(1994b): Programa de mejoramiento de la calidad y equidad de la educación, 1995-2000. Fundamentos, estrategias y componentes. Volumen 1 y 2. Santiago: MINEDUC. 
(1998a): «Objetivos fundamentales y contenidos mínimos obligatorios de la educación media». Decreto №220. Santiago: MINEDUC.

(1998b): «Resultados consulta nacional a dirigentes estudiantiles acerca del marco curricular de la educación media». Santiago: MINEDUC.

(1999): «Agenda liceos 1999». Santiago: MINEDUC.

(s/f): «La Reforma. Un cambio sin precedentes para la vida de los estudiantes». Santiago: MINEDUC.

Weinstein, José (1994): «Los jóvenes y la educación media». Primer informe nacional de juventud. Santiago: Instituto Nacional de la Juventud. 